\title{
Recent challenges facing patients with preexisting chronic liver disease in the era of the COVID-19 pandemic
}

\author{
Iliana Mani, Alexandra Alexopoulou \\ Medical School, National and Kapodistrian University of Athens, Hippokration General Hospital, Athens, Greece
}

\section{Abstract}

\section{Introduction}

The novel coronavirus, named SARS-CoV-2, is responsible for COVID-19 pandemic. SARS-CoV-2 uses the angiotensin-converting enzyme-2 (ACE2) receptor for its entry into host cells. Then, the cellular transmembrane protease serine 2 (TMPRSS2) cleaves the SARS-CoV-2 spike protein, allowing fusion of cellular and viral membranes [1]. The ACE2 receptor is present in more than $80 \%$ of the alveolar cells of the lungs $[2,3]$, the gastrointestinal tract, $60 \%$ of cholangiocytes, the endothelium of small blood

$2^{\text {nd }}$ Department of Medicine, Medical School, National and Kapodistrian University of Athens, Hippokration General Hospital, Athens, Greece (Iliana Mani, Alexandra Alexopoulou)

\section{Conflict of Interest: None}

Correspondence to: Iliana Mani, MD, $2^{\text {nd }}$ Department of Medicine, Medical School, National and Kapodistrian University of Athens, Hippokration General Hospital, 114 Vas. Sophias Ave., Athens 11527, Greece, e-mail: ilianamani@windowslive.com

Received 18 January 2021; accepted 25 February 2021; published online 27 May 2021

DOI: https://doi.org/10.20524/aog.2021.0628 vessels in the liver and to a smaller extent in hepatocytes, indicating that the liver could be a potential target for SARSCoV-2 [2] (Fig. 1).

Liver histological features in COVID-19 include microvesicular steatosis, mild lobular and portal inflammatory infiltrate, or mild sinusoidal dilatation and focal macrovesicular steatosis [4]. Potential mechanisms inducing liver damage include a direct cytopathic effect of the virus, uncontrolled immune reaction, sepsis, drug-induced liver injury, ischemic liver injury, and deterioration of underlying chronic liver disease (CLD) [2,5] (Fig. 1).

Alanine aminotransferase (ALT), total bilirubin and $\gamma$-glutamyl transferase elevation were evident in a total of $28 \%, 18 \%$ and $72 \%$ of COVID-19 patients, respectively [6,7]. Liver dysfunction has been considered a bad prognostic factor in patients with COVID-19, even after adjustment for multiple cofactors [8]. Elevated aspartate aminotransferase (AST) or ALT levels were observed in $18 \%$ or $20 \%$ and $28 \%$ or $39 \%$ of patients with non-severe and severe liver disease, respectively [9]. In another study, AST elevation was found in $25 \%$ or $62 \%$ of patients not requiring or requiring intensive care unit (ICU) admission, respectively [10]. Although some studies have suggested that abnormal liver function tests were not associated with mortality [11,12], close monitoring of liver biochemical tests is advised [12]. The aim of this review 


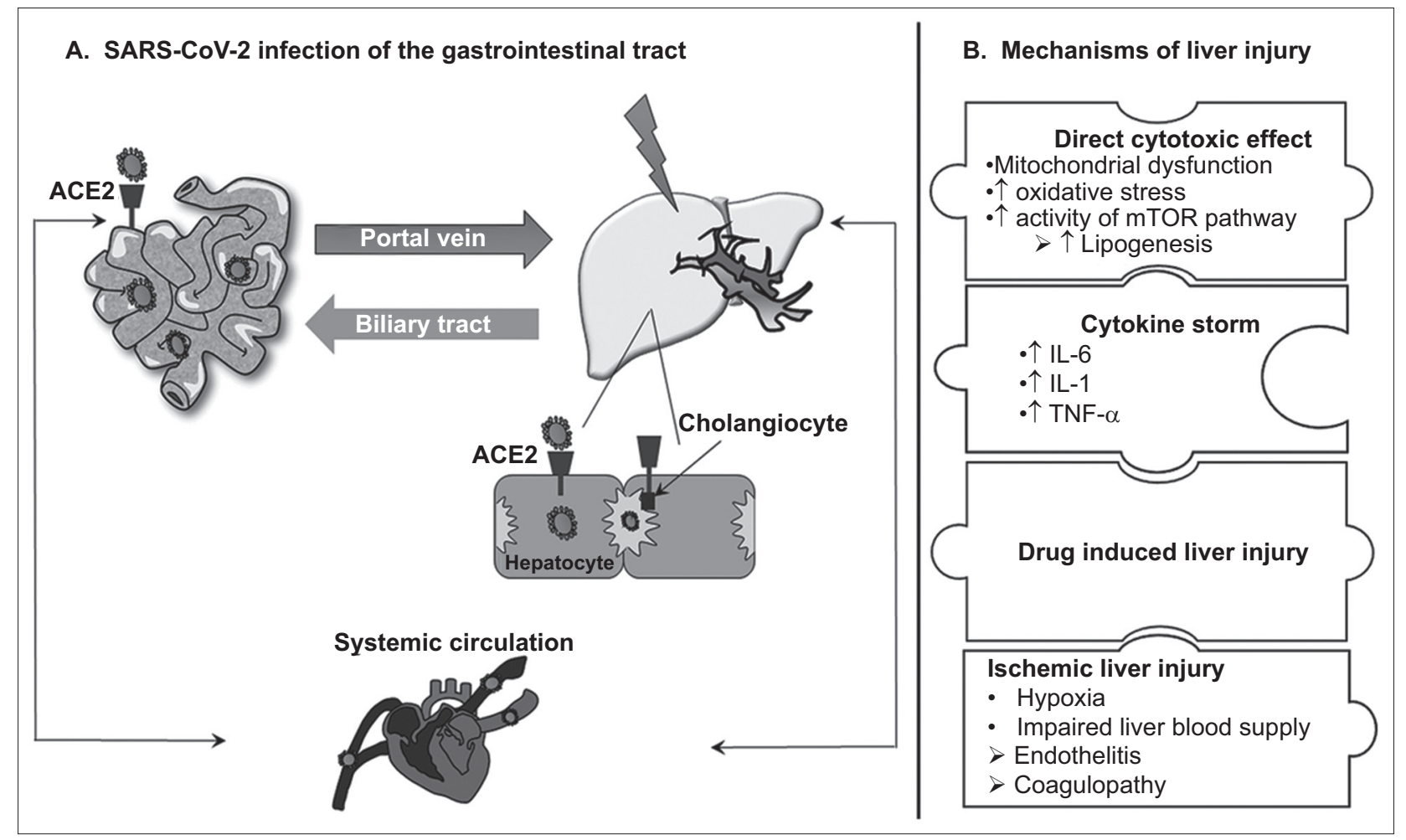

Figure 1 Possible mechanisms for SARS-CoV-2-induced liver injury ACE2, angiotensin-converting enzyme 2; mTOR, mammalian target of rapamycin; IL, interleukin; TNF- $\alpha$, tumor necrosis factor- $\alpha$

was to investigate the impact of COVID-19 infection on the management, course, and outcome of CLD.

\section{Search strategy}

We searched PubMed for the search terms "coronavirus" or "COVID-19" or "SARS-CoV-2" and "liver disease" or "viral hepatitis" or "non-alcoholic steatohepatitis" or "cirrhosis" or "alcoholic hepatitis" or "liver transplantation" or "autoimmune hepatitis", with no time limits. Only studies in the English language were included. We reviewed the relevant studies and scrutinized the reference lists of the included studies to identify additional references.

\section{Impact of COVID-19 on the management of patients with preexisting liver disease}

\section{Impact of COVID-19 on hepatitis elimination programs}

Hepatitis B and C affect more than 320 million people globally and can result in CLD and mortality from cirrhosis and hepatocellular carcinoma (HCC). More than 248 million individuals are chronically infected with hepatitis $\mathrm{B}$ virus (HBV), and over 700,000 deaths annually are attributed to HBV. On the other hand, 80 million people are chronically infected with hepatitis $\mathrm{C}$ virus (HCV), resulting in nearly 500,000 deaths per year [13].

The World Health Organization (WHO) adopted a target in 2016 to eliminate hepatitis by 2030, by achieving a $90 \%$ reduction in new infections and a $65 \%$ reduction in liver-related deaths [13]. The World Hepatitis Alliance assessed the effects of the COVID-19 pandemic on viral hepatitis services and on people with chronic hepatitis [14]. Civil society organizations that are main contributors to national hepatitis elimination programs reported that their services were affected by the crisis, including halting screening programs and communitybased education [14].

Fewer people have access to testing facilities and many testing facilities have been closed. Moreover, people avoid visiting healthcare facilities for fear of COVID-19. In addition, people on hepatitis treatment have limited access to their medication. Travel restrictions make patients living in remote rural communities unable to access hepatitis medication. As a result, they reported delays in taking their antiviral drugs for chronic $\mathrm{HBV}$ or starting $\mathrm{HCV}$ treatment. Inadequate information about COVID-19 is provided for persons living with viral hepatitis, leaving them reluctant to seek advice from hepatitis healthcare facilities [14].

Disruptions to HCV elimination programs were reported in Italy and Egypt, where delays in birth cohort screening for hepatitis were recorded in the former and reduction or halting of screening programs (including children, pregnant women, foreigners and prisoners) were reported in the latter [15] (Table 1). It was estimated that according to the "one-year 
Table 1 Direct and indirect effects COVID-19 on patients with preexisting liver diseases

\begin{tabular}{|c|c|c|}
\hline $\begin{array}{l}\text { Direct effects on preexisting liver } \\
\text { diseases }\end{array}$ & $\begin{array}{l}\text { Collateral effects due to overwhelmed health systems, social } \\
\text { distancing and isolation }\end{array}$ & $\begin{array}{l}\text { No or limited evidence for } \\
\text { significant effects }\end{array}$ \\
\hline $\begin{array}{l}\text { Cirrhosis } \\
\text { - Increased risk for severe COVID-19 } \\
\text { and death [66-69] } \\
\text { - Increased risk for decompensation/ } \\
\text { acute-on-chronic liver failure }[66,68]\end{array}$ & $\begin{array}{l}\text { - Delays in viral hepatitis elimination programs }[14,15,16] \\
\text { - Deferrals of liver clinic visits }[17,18] \\
\text { - Inadequate surveillance of cirrhosis complications and } \\
\text { HCC }[17,18] \\
\text { - Inadequate management of hepatocellular carcinoma }[24,25]\end{array}$ & $\begin{array}{l}\text { - Liver transplant recipients }{ }^{*}[23] \\
\text { - Autoimmune hepatitis* }[34-36] \\
\text { - Chronic viral hepatitis without } \\
\text { cirrhosis }^{* *}[25,53-56]\end{array}$ \\
\hline $\begin{array}{l}\text { NAFLD/NASH } \\
\text { - Increased risk for severe COVID-19 } \\
{[37,38,39,40]}\end{array}$ & $\begin{array}{l}\text { - Postponement of liver transplantation activities [19-22] } \\
\text { - Limited resources for chronic liver diseases } \\
\text { - Possible increased risk or relapse of alcoholic liver disease [46] }\end{array}$ & \\
\hline
\end{tabular}

delay" scenario no patients would be newly diagnosed in 2020 and no regions were expected to meet the WHO target for new HCV diagnoses and treatments by 2030. It was calculated that this delay would apply to only $89 \%$ of the $2015 \mathrm{HCV}$ population being diagnosed by 2030 , and these $11 \%$ missed diagnoses would result in approximately 45,000 excess HCC cases and 72,000 excess liver-related deaths predicted in the next 10 years, globally. A country previously considered to have completed its elimination targets in due time but lost progress is Italy, where there was a $35 \%$ reduction in patients initiating HCV treatment in 2019 vs. 2018 [15].

Kondili et al, using a Markov model for liver-disease progression, quantified the effect the deferrals of HCV cure would have on disease outcome [16]. They found that the numbers of additional cases of advanced liver disease and HCV-related deaths increased with the length of delay. In Italy, for delays of 3, 6, 9 and 12 months, advanced liver disease cases increased by 2, 5, 7 and 10, respectively, and the same increases were demonstrated for HCV-related deaths per 1000 standardized patients. In the United Kingdom, increases of 3, 8, 12 and 17 advanced liver disease cases and 1, 4, 5 and $7 \mathrm{HCV}$-related deaths per 1000 standardized patients was computed. The investigators stressed that healthcare systems were overwhelmed by patients with COVID-19 and limited care resources were directed particularly to their care (Table 1). However, they advised that the ambitious target set by the WHO in 2016 for viral hepatitis should not stop, and patients with chronic hepatitis $\mathrm{C}$ should be diagnosed and treated in time. If they remain undiagnosed and untreated, patients with less severe stages will proceed further and those with severe fibrosis will die from a liver-related condition.

Toyoda et al obtained data on the number of outpatient clinic visits, abdominal ultrasound, computed tomography and magnetic resonance imaging at 3 medical centers-in the United States (US), Japan, and Singapore-during certain periods of 2018, 2019 and 2020 [17]. They found significant decreasing trends in the clinic visits for patients with chronic hepatitis B and C. HCC/cirrhosis visits dropped by about $40 \%$ overall and by $47 \%$ at the US site (Table 1), and the number of imaging tests decreased significantly. The authors warned of inadequate HCC surveillance in patients with chronic hepatitis, prone to developing HCC, and urged care providers to recall patients for monitoring, especially concerning HCC surveillance.

\section{Impact of COVID-19 on the management of patients with advanced CLD}

The experience of Italian doctors regarding the impact of COVID-19 in the management of cirrhosis and its complications is described in a web-based survey by the active members of the Italian Association for the Study of the Liver, encompassing all Italian Liver Units [18]. The reduction in daily outpatient activity was linked to the severity of the underlying liver disease. Screening of esophageal varices was reduced or postponed in $46 \%$ and $20 \%$ of cases, respectively, while for endoscopic band ligation as primary or secondary prophylaxis for variceal hemorrhage the figures were 33\% and $12 \%$, respectively. A preference for remote contact was recorded in $40 \%, 44 \%, 25 \%$ and $17 \%$ of patients with chronic hepatitis, compensated cirrhosis, HCC and decompensated cirrhosis, respectively. A 30\% reduction in pre-transplant assessment and $44 \%$ deferral in post-transplant reviews were reported by Liver Transplant Centers (Table 1) [18].

More specifically, COVID-19 pandemic had immediate effects on liver transplantation worldwide, due to the vast number of people seeking medical care and the excruciating burden on intensive care facilities [19]. Although some large centers worldwide opted to maintain routine liver transplantation activities at the same level as usual [20], others failed to do so [21]. Most transplant centers were constrained to limit transplant activity because of low rates of deceased donation, limited resources, decreased availability of ICU beds, a shortage of ICU specialists for liver transplant programs, reduction of use of marginal grafts, or exclusion of donors on clinical suspicion of respiratory infection or positive contact history [22]. High waiting-list mortality is expected as one of the consequences of all the above. Hence, protocol changes in response to the pandemic have been suggested by most liver transplantation specialists worldwide [22].

Regarding liver transplant recipients, an International registry study including patients with confirmed SARS-CoV-2 infection from 2 international registries found satisfactory outcomes in 151 liver transplant recipients with COVID-19 
compared to 627 with COVID-19 who had not received a liver transplant (control group). Despite the fact that ICU admission and invasive ventilation were more common in liver transplant recipients compared to the control group, the former had a lower mortality rate (19\% vs. $27 \%)$. In the propensity score matched analysis (adjusting for multiple covariates), liver transplantation did not increase the risk of death [23].

The disruption of health systems as a consequence of the pandemic was highlighted by a French study dealing with changes in the diagnosis and management of HCC during the first 6 weeks of the pandemic, in comparison with the same time period in 2019 [24]. Initially, in 2020, significantly fewer patients were referred to oncologists. Moreover, patients first diagnosed with HCC in 2020 had larger tumor burden, as indicated by differences in tumor size-49 (25-80) $\mathrm{mm}$ vs. 32 (22-60) mm-but did not differ as regards Barcelona cancer stage. In the total cohort, therapeutic intervention was delayed by $\geq 1$ month in $21.5 \%$ in 2020 vs. $9.5 \%$ in 2019 . The difference was even wider for patients with known HCC, estimated at $23.3 \%$ vs. $4.7 \%$, respectively (Table 1 ).

The above observations led to amendment of the existing guidelines for surveillance and treatment of HCC in the era of COVID-19. Emphasis is placed on individualized decision-making, taking into consideration the local spread of COVID-19, the accessibility and availability of healthcare resources, and the patient's risk factors for severe COVID-19 disease, stage of HCC and severity of liver impairment $[25,26]$. According to the European Association for the Study of Liver Disease (EASL), care for HCC should be maintained according to guidelines, continuing systemic treatment and evaluation for HCC [27].

\section{The impact of COVID-19 on the course and prognosis of patients with preexisting liver disease}

\section{Autoimmune liver diseases}

Concerns have been raised about the management of autoimmune liver diseases during the pandemic. There are limited data to draw safe conclusions regarding primary biliary cholangitis and primary sclerosing cholangitis. For the diagnosis of autoimmune hepatitis (AIH), the EASL and the American Association for the Study of Liver Diseases (AASLD) recommend following the existing guidelines in areas with a low prevalence of COVID-19 [27,28]. A different approach could be to postpone liver biopsy and initiate immunosuppressive therapy, based on the presence of biochemical and immunological tests compatible with $\mathrm{AIH}$, in order to avoid exposing patients to the hospital environment [29].

Regarding the impact of immunosuppressive therapy, the hypothesis that immunosuppressed patients are more vulnerable to SARS-CoV-2 infection compared to the general population cannot be justified [30]. In particular, systemic corticosteroids were found to be an independent risk factor for severe COVID-19 in patients with inflammatory bowel disease [31] and rheumatologic diseases [32,33].

The outcome of patients with preexisting $\mathrm{AIH}$ and COVID-19 has been investigated in a few studies. A center in northern Italy studied 148 patients with autoimmune liver disease, the majority of whom (90\%) had a diagnosis of $\mathrm{AIH}$ and were under immunosuppressive therapy. The incidence of COVID-19 did not differ compared to the general population. Overall, $26 \%$ of patients reported symptoms suggestive of COVID-19 but did not require hospitalization. There were only 4 confirmed cases, 3 of which were hospitalized. Only 1 patient, 78 years old with comorbidities, died [34]. Similar results were described in a second Italian study of 10 patients with COVID-19 and AIH under immunosuppressive regimens, mainly corticosteroids. Only 1 patient died, but had a history of decompensated liver disease, and another one experienced relapse of AIH after corticosteroid discontinuation [35]. In a recent International Registry study, 70 patients with AIH (taking one or more immunosuppressive drugs) and SARS-CoV-2 infection were compared with patients with CLD without AIH (non-AIH CLD). There was no difference between AIH and non-AIH CLD regarding hospitalization, ICU admission and death. In the propensity score matched analysis, no increase in the risk for adverse outcomes including death was demonstrated in AIH vs. non AIH CLD patients [36] (Table 1).

Although the results are insufficient and not well documented, the EASL and AASLD recommendations suggest continuation of immunosuppressive regimens without any dose modification in patients without COVID-19. To avoid exposure to high doses of corticosteroids, it is recommended to use budesonide as first-line agent to achieve remission in non-cirrhotic patients with exacerbation of AIH [27]. The statements differ for patients with AIH who become infected with COVID-19. According to the EASL recommendations, switching to dexamethasone or adding it to the basic corticosteroid should be an option only for patients with severe disease, but there were no instructions for the other immunosuppressive agents. According to the AASLD, corticosteroids as well as azathioprine or mycophenolate mofetil should be reduced to the lowest possible doses, particularly if the course of COVID-19 is severe [28].

\section{Nonalcoholic fatty liver disease (NAFLD) and alcohol- related liver disease (ALD)}

Multiple studies demonstrated that the individual components of metabolic syndrome (MetS) were independent risk factors for severe COVID-19. In a US study of 8885 COVID-19 patients (215 with MetS), the incidence of COVID-19 was higher in the MetS group. Among all comorbid metabolic conditions, including hypertension, hyperlipidemia, obesity and diabetes mellitus, nonalcoholic steatohepatitis (NASH) had the strongest association with COVID-19 [37]. In a Chinese retrospective study of 202 patients with COVID-19, NAFLD, other comorbidities, age over 60 years, male sex, and 
high body mass index (BMI) were associated with a more severe course of COVID-19 [38]. Other Chinese investigators have shown that the risk of severe COVID-19 illness in NAFLD patients was higher in patients younger than 60 years, even after adjusting for comorbidities $[39,40]$ (Table 1). Apart from age, moderate/high noninvasive fibrosis markers of NAFLD, such as FIB-4 and NAFLD fibrosis score [41], and the inflammation marker neutrophil-to-lymphocyte ratio were also associated with poor outcomes [42].

An upregulation of ACE2 and TMPRSS2 genes was observed in the liver of obese patients with NASH [43]. Moreover, ACE2 and TMPRSS2 expression was positively correlated with NAFLD activity score [44]. Another interpretation is that both NAFLD and COVID-19 derange the immune response in a similar way. Specifically, NAFLD, as well as obesity, is characterized by immune dysfunction, expressed as activation of macrophages and adipocytes leading to release of proinflammatory cytokines and chemokines. In subjects with MetS, the chronic low-grade inflammatory state could further deteriorate the inflammatory response to SARS-CoV-2 infection, inducing a hypersensitivity state and cytokine storm [45] (Fig. 2).

Patients with ALD may be among the populations affected the most severely. This population is at high risk for severe COVID-19 infection, given their impaired immune system, neglected general health with multiple comorbidities, social isolation resulting in psychological disturbances, increased drinking or relapse during lockdown, and difficulty asking for assistance and supportive care. Specialists fear that the COVID-19 pandemic will be followed by a dramatic rise in alcohol relapse and in admissions for decompensated ALD or acute alcoholic hepatitis, and an increase in patients with newly diagnosed ALD. Thus, they advise the implementation of preemptive strategies to contain this anticipated problem [46].

\section{Management and course of patients with chronic viral hepatitis (except cirrhosis) and infection with SARS-CoV-2}

Chronic HBV infection is characterized by functional exhaustion of $\mathrm{HBV}$-specific $\mathrm{CD} 8+\mathrm{T}$-cells due to $\mathrm{HBs}$ antigenemia and failure to neutralize circulating virions as a result of an insufficient B-cell response [47]. On the other hand, lymphocytopenia, especially reduced $\mathrm{CD} 4^{+}$and $\mathrm{CD} 8^{+} \mathrm{T}$ cell counts on hospital admission, is predictive of COVID-19 progression [48]. Hence, dysfunctional T-lymphocytes present in chronic HBV infection might be expected to be associated with a more severe COVID-19 course [49-51]. Zou et al demonstrated a poor prognosis in 105 patients with chronic HBV infection who had been co-infected with SARSCoV-2 [52]. However, no control group was included in the study (SARS-CoV-2 without HBV) and baseline data such as clinical stage (cirrhosis or not) and active HBV replication status, as well as the administration of antiviral HBV drugs during hospitalization, were not reported [53]. Chen et al found no significant differences in liver function parameters, hospitalization time, discharge rate, severity or mortality in patients with pre-existing chronic $\mathrm{HBV}$ infection compared

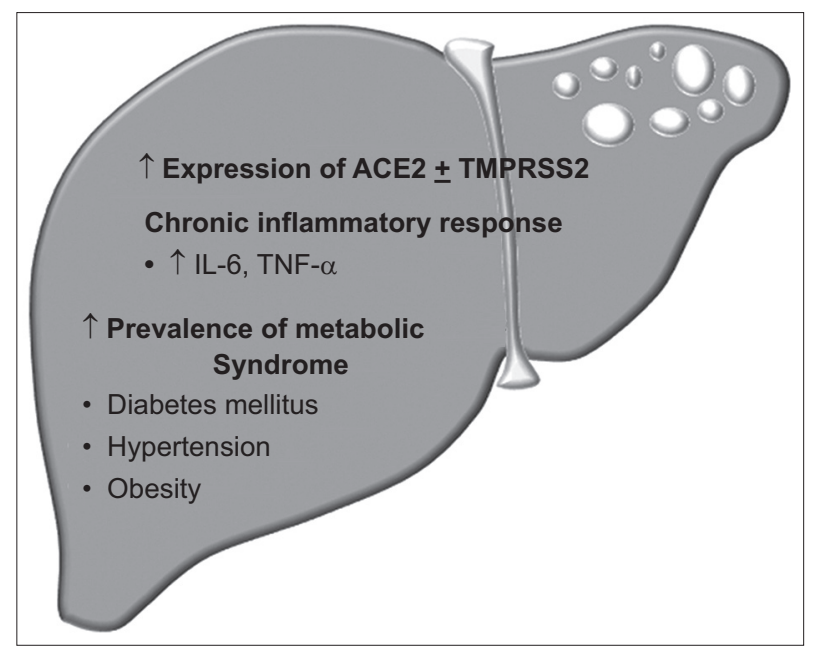

Figure 2 Mechanisms likely to predispose patients with nonalcoholic fatty liver disease to a more severe course of COVID-19 $A C E 2$, angiotensin-converting enzyme 2; TMPRSS2, transmembrane protease serine 2; IL, interleukin; TNF- $\alpha$, tumor necrosis factor-a

to those without [54]. Zhang et al presented 23 patients hospitalized for SARS-CoV-2 who had chronic HBV infection. A severe course of COVID-19 was reported in $34 \%$, but all of them were discharged [55].

Abnormalities in liver function tests have been described in patients with chronic HBV infection hospitalized for COVID-19 [56]. The administration of corticosteroids and/or tocilizumab in patients with chronic HBV infection without antiviral prophylaxis and the potential hepatotoxicity of lopinavir/ritonavir may be involved [8] (Table 1). The status of viral hepatitis has to be known in patients who are going to receive immunosuppression with dexamethasone and/or tocilizumab [25]. Current guidelines recommend not deferring treatment in patients with chronic active hepatitis B without COVID-19. Given the unknown impact of interferon- $\alpha$ on systemic inflammation associated with COVID-19, treatment with nucleos(t)ide analogs is preferred [27]. In addition, it is not advisable to stop antiviral drugs in patients with chronic HBV infection suffering from COVID-19, in view of the high risk of reactivation when stopping nucleos(t)ide analogs.

Regarding drug-drug interactions, it is necessary to check for potential hepatotoxicity reactions between agents administered to treat both SARS-CoV-2 and HBV, using proper online platforms. For example, coadministration of lopinavir/ ritonavir with tenofovir disoproxil or alafenamide may increase tenofovir concentrations by $32-51 \%$ or $275-316 \%$, respectively. Moreover, close monitoring of renal function is mandatory, and in the case of renal impairment a switch to entecavir is required [25].

Direct acting antivirals (DAAs) used for the treatment of $\mathrm{HCV}$ were also investigated for the treatment of SARS-CoV-2. As both viruses use RNA-dependent RNA polymerase (RdRp) for their replication, and nucleotide analogs can be incorporated into RNA by SARS-CoV-2 RdRp, the incorporation of some of them may lead to chain termination. Many researchers have evaluated the incorporation efficiency of nucleotide 
analogs compared to natural nucleotide [57-63]. However, the incorporation of sofosbuvir is very low, suggesting that sofosbuvir may not be very effective in treating SARS-CoV-2 infection [64]. In contrast, another report stated that sofosbuvir terminated RNA and resisted removal by the exonuclease to a substantially higher extent than RNA terminated by remdesivir [65]. Clinical trials concerning the efficacy of DAAs (sofosbuvir with daclatasvir and/or ledipasvir) in the treatment of COVID-19 remain to be completed (NCT04497649, NCT04535869, NCT04561063, NCT04468087, etc.).

In patients who have recently been diagnosed with chronic hepatitis C, deferral of HCV therapy until COVID-19 clearance is recommended [27]. In case HCV treatment has already been initiated, it can be continued while monitoring for drug-drug interactions [27]. More specifically, lopinavir/ritonavir is expected to increase the concentrations of protease inhibitors in protease-inhibitor-containing regimens (glecaprevir/ pibrentasvir, elbasvir/grazoprevir, sofosbuvir/velpatasvir) and consequently a hepatotoxicity reaction may develop. Hence, lopinavir/ritonavir should not be added when the patient is taking the above DAAs [25].

\section{Impact of COVID-19 on the mortality of patients with liver cirrhosis}

COVID-19 is associated with a high risk of liver function deterioration and death in patients with liver cirrhosis (Tables 1,2). In a study from Italy that included 50 patients with cirrhosis (38\% viral hepatitis-related, $48 \%$ decompensated cirrhosis), the 30 -day mortality rate was $34 \%$. Liver disease severity deteriorated after infection with coronavirus and the proportion of patients with model for end-stage liver disease (MELD) score $\geq 15$ increased from $13 \%$ to $26 \%$, while $46 \%$ of compensated cirrhotics decompensated and acute-on-chronic liver failure (ACLF) developed in $28 \%$. The death rate was higher in patients with a high MELD score $(\geq 15)$ or Chronic Liver Failure Consortium organ failure score $\geq 9$. The death rate in cirrhotics with COVID-19 was higher compared to either cirrhotics with common infections (34\% vs. $17 \%$ ) or to another group with COVID-19 without cirrhosis (34\% vs. $20 \%$ ) [66]. In another investigation from 21 countries, including 103 patients with cirrhosis, the mortality rate from COVID-19 was $39.8 \%$ in cirrhotics compared with $12.2 \%$ in

Table 2 Characteristics and findings in studies concerning COVID-19 in patients with cirrhosis

\begin{tabular}{|c|c|c|c|c|c|c|c|}
\hline $\begin{array}{l}\text { Author } \\
\text { [Ref.] }\end{array}$ & $\begin{array}{l}\text { Date } \\
\text { of } \\
\text { study }\end{array}$ & Study design & Patients $(\mathrm{N})$ & $\begin{array}{l}\text { Deterioration } \\
\text { of chronic liver } \\
\text { disease }\end{array}$ & $\begin{array}{l}\text { Severe } \\
\text { COVID-19 }\end{array}$ & Death rate & $\begin{array}{l}\text { Predictors of } \\
\text { mortality }\end{array}$ \\
\hline $\begin{array}{l}\text { Iavarone } \\
\text { et al } \\
{[66]}\end{array}$ & 2020 & $\begin{array}{l}\text { Multicenter } \\
\text { retrospective }\end{array}$ & $\begin{array}{l}\text { - } 50 \text { cirrhotics with } \\
\text { COVID-19 }\end{array}$ & $\begin{array}{l}\text { - Patients with } \\
\text { MELD } \geq 15 \\
\text { increased from } \\
13 \% \text { to } 26 \% \\
\text { - ACLF in } 28 \% \\
\text { - Liver-related } \\
\text { mortality in } 12 \%\end{array}$ & $\begin{array}{l}\text { - Respiratory } \\
\text { support in } \\
71 \% \\
\text { - COVID- } \\
\text { 19-related } \\
\text { mortality in } \\
25 \%\end{array}$ & - $34 \%$ overall & $\begin{array}{l}\text { CLIF-C OF } \\
\text { and moderate/ } \\
\text { severe lung } \\
\text { failure or } \\
\text { MELD, CLIF-C } \\
\text { ACLF and } \\
\text { moderate/ } \\
\text { severe lung } \\
\text { failure }\end{array}$ \\
\hline $\begin{array}{l}\text { Moon } \\
\text { et al } \\
{[67]}\end{array}$ & 2020 & $\begin{array}{l}\text { Multicenter } \\
\text { retrospective }\end{array}$ & $\begin{array}{l}\text { All infected with } \\
\text { COVID-19 } \\
\text { - } 103 \text { cirrhotics } \\
\text { - } 49 \text { with CLD } \\
\text { without cirrhosis }\end{array}$ & $\begin{array}{l}\text { - Decompensation } \\
\text { in } 36.9 \% \\
\text { - Liver-related } \\
\text { mortality in } 12.2 \%\end{array}$ & $\begin{array}{l}\text { - COVID-19 } \\
\text { lung disease in } \\
78.7 \% \\
\text { - ICU admission } \\
\text { in } 23 \% \\
\text { - Invasive } \\
\text { ventilation in } \\
17.5 \% \\
\text { - Non-invasive } \\
\text { ventilation in } \\
18.6 \%\end{array}$ & $\begin{array}{l}\text { - } 12.2 \% \text { in } \\
\text { CLD without } \\
\text { cirrhosis } \\
\cdot 39.8 \% \text { in } \\
\text { cirrhotics } \\
\text { - } 23.9 \% \text { in } \\
\text { CTP class A } \\
\text { - } 43.3 \% \text { in } \\
\text { CTP class B } \\
\text { - } 63 \% \text { in CTP } \\
\text { class C }\end{array}$ & $\begin{array}{l}\text { Age, obesity } \\
\text { and hepatic } \\
\text { decompensation }\end{array}$ \\
\hline $\begin{array}{l}\text { Bajaj } \\
\text { et al } \\
{[70]}\end{array}$ & 2020 & $\begin{array}{l}\text { Multicenter } \\
\text { retrospective }\end{array}$ & $\begin{array}{l}\text { - } 37 \text { with cirrhosis } \\
\text { plus COVID-19 } \\
\text { - } 108 \text { with } \\
\text { COVID-19 alone } \\
\text { - } 127 \text { with cirrhosis } \\
\text { alone }\end{array}$ & $\begin{array}{l}\text { - Similar ACLF } \\
\text { related mortality } \\
\text { rates between } \\
\text { cirrhosis groups }\end{array}$ & $\begin{array}{l}\text { Similar rates in } \\
\text { ICU transfer, } \\
\text { mechanical } \\
\text { ventilation } \\
\text { and central } \\
\text { line placement } \\
\text { between } \\
\text { COVID-19 } \\
\text { groups }\end{array}$ & $\begin{array}{l}\text { - } 30 \% \text { in } \\
\text { cirrhosis plus } \\
\text { COVID-19 } \\
\text { - } 12 \% \\
\text { COVID-19 } \\
\text { alone } \\
\text {-20\% in } \\
\text { cirrhosis alone }\end{array}$ & \\
\hline
\end{tabular}

(Contd...) 
Table 2 (Continued)

\begin{tabular}{|c|c|c|c|c|c|c|c|}
\hline $\begin{array}{l}\text { Author } \\
\text { [Ref.] }\end{array}$ & $\begin{array}{l}\text { Date } \\
\text { of } \\
\text { study }\end{array}$ & Study design & Patients (N) & $\begin{array}{l}\text { Deterioration } \\
\text { of chronic liver } \\
\text { disease }\end{array}$ & $\begin{array}{l}\text { Severe } \\
\text { COVID-19 }\end{array}$ & Death rate & $\begin{array}{l}\text { Predictors of } \\
\text { mortality }\end{array}$ \\
\hline $\begin{array}{l}\text { Singh } \\
\text { et al } \\
{[69]}\end{array}$ & 2020 & $\begin{array}{l}\text { Multicenter } \\
\text { retrospective }\end{array}$ & $\begin{array}{l}\text { All infected with } \\
\text { COVID-19 } \\
\text { - } 2530 \text { without CLD } \\
\text { - } 250 \text { with CLD } \\
\text { including } \\
\text { - } 50 \text { with cirrhosis }\end{array}$ & & & $\begin{array}{l}\text { Patients with } \\
\text { cirrhosis had a } \\
\text { higher RR for } \\
\text { death vs. those } \\
\text { without CLD } \\
\text { (RR 4.6, 95\%CI } \\
\text { 2.6-8.3; } \mathrm{P}<0.001 \text { ) }\end{array}$ & \\
\hline $\begin{array}{l}\text { Qi et al } \\
\text { [71] }\end{array}$ & 2020 & $\begin{array}{l}\text { Multicenter } \\
\text { retrospective }\end{array}$ & $\begin{array}{l}\text { All infected with } \\
\text { COVID-19 } \\
\text { - } 16 \text { CTP class A } \\
\text { - } 3 \text { CTP class B } \\
\text { - } 2 \text { CTP class C }\end{array}$ & & $\begin{array}{l}\text { Respiratory } \\
\text { failure was the } \\
\text { cause of death }\end{array}$ & $23.8 \%$ & $\begin{array}{l}\text { Non-survivors } \\
\text { had lower } \\
\text { platelets and } \\
\text { higher total } \\
\text { bilirubin vs. } \\
\text { survivors }\end{array}$ \\
\hline $\begin{array}{l}\text { Sarin } \\
\text { et al } \\
{[68]}\end{array}$ & 2020 & $\begin{array}{l}\text { Multicenter } \\
\text { retrospective }\end{array}$ & $\begin{array}{l}\text { All infected with } \\
\text { COVID-19 } \\
\text { - } 43 \text { cirrhotics } \\
\text { - } 185 \text { with CLD } \\
\text { without cirrhosis }\end{array}$ & $\begin{array}{l}\text { - ACLF in } 11.6 \% \\
\text { - Acute } \\
\text { decompensation } \\
\text { in } 9 \%\end{array}$ & $\begin{array}{l}\text { Severe } \\
\text { COVID-19 } \\
\text { - } 20 \% \text { in } \\
\text { compensated } \\
\text { cirrhosis } \\
\text { - } 33 \% \text { in } \\
\text { decompensated } \\
\text { cirrhosis } \\
\text { - } 11.5 \% \text { in CLD } \\
\text { without cirrhosis }\end{array}$ & $\begin{array}{l}\text { - } 2.1 \% \text { in CLD } \\
\text { without } \\
\text { cirrhosis } \\
\text { - } 16.7 \% \text { in } \\
\text { cirrhosis in } \\
\text { overall } \\
\text { - } 43 \% \text { in } \\
\text { decompensated } \\
\text { cirrhosis }\end{array}$ & $\begin{array}{l}\text { Poor outcome } \\
\text { for CTP score } \\
\geq 9\end{array}$ \\
\hline
\end{tabular}

Case reports are not included

ACLF, acute-on-chronic liver failure; CLD, chronic liver disease; CTP, Child-Turcotte-Pugh score; ICU, intensive care unit; CLIF-C OF, Chronic Liver Failure Consortium organ failure; $M E L D$, model for end-stage liver disease; $R R$, risk ratio; CI, confidence interval

patients who had CLD without cirrhosis. Mortality was strongly related to baseline Child-Pugh score $(23.9 \%, 43 \%$ and $63 \%$ in $\mathrm{A}, \mathrm{B}$, and $\mathrm{C}$, respectively) or MELD score. In addition, hepatic decompensation was associated with a higher risk of death compared to compensated cirrhosis (63.2\% vs. 26.2\%) [67]. Similarly, in an Asian study that evaluated 43 cirrhotics and 185 patients who had CLD without cirrhosis, ACLF developed in $11.6 \%$ and acute decompensation in $9 \%$. The death rate was $16.7 \%$ for cirrhosis overall and $43 \%$ in patients with decompensated cirrhosis. A Child-Pugh score $\geq 9$ predicted a poor outcome in patients with cirrhosis [68]. In a large US registry with a total of 2780 patients with COVID-19, 9\% had preexisting CLD and 1.8\% were diagnosed with cirrhosis [69]. Patients with liver disease had a higher hospitalization and mortality risk (risk ratio [RR] 3.0,95\% confidence interval [CI] 1.5-6.0; $\mathrm{P}=0.001$ ) compared to patients without liver disease, after propensity score matched analysis for age, race, nicotine use, BMI, hypertension and diabetes. The risk increased further in patients with cirrhosis compared to those without liver disease ( $\mathrm{RR}$ 4.6, 95\% CI 2.6-8.3; $\mathrm{P}<0.001$ ). In a multicenter North American trial where 3 groups were compared, patients with cirrhosis and COVID-19 had higher mortality compared to those who had COVID-19 without cirrhosis, but did not differ significantly from those hospitalized with complications of cirrhosis ( $30 \%$ vs. $13 \%$ vs. $20 \%$, respectively). Chronic hepatitis C, alcohol-related liver disease or both were the most prevalent etiologies. ACLF development and length of stay did not differ between cirrhosis groups. ICU transfer was higher in patients with cirrhosis and COVID-19 [70]. In a Chinese study involving 21 cirrhotics, no significant differences were found between survivors and non-survivors regarding disease severity scores (MELD, Child-Pugh). However, the sample was small and most patients had Child-Pugh score A (Child-Pugh $A=16$, $\mathrm{B}=3$ and $\mathrm{C}=2$ ), so no safe conclusions could be drawn [71].

\section{Concluding remarks}

The severe crisis generated by the overwhelmed healthcare systems has diverted the attention of healthcare professionals from viral hepatitis elimination and liver transplantation programs, HCC surveillance and management of advanced liver disease, to COVID-19 care. Moreover, patients with CLD avoid attending healthcare facilities, either because of travel restrictions or for fear of becoming infected. COVID-19 does not appear to run a more severe course in patients with chronic viral hepatitis without cirrhosis. On the other hand, patients with NAFLD/NASH, with or without comorbidities, are at risk for a more severe COVID-19 outcome, particularly those with moderate/advanced fibrosis. Similarly, patients with cirrhosis (regardless of etiology) were demonstrated to have a high mortality rate when infected with SARS-CoV-2. The mortality rate from COVID-19 was related to the severity of 
liver cirrhosis. Finally, patients with alcohol-use disorder or alcohol-related liver disease may deteriorate and professionals should expect an increase in alcohol-risk behavior, resulting in newly diagnosed cases or a relapse of old ones.

\section{References}

1. Hoffmann M, Kleine-Weber H, Schroeder S, et al. SARS-CoV-2 cell entry depends on ACE2 and TMPRSS2 and is blocked by a clinically proven protease inhibitor. Cell 2020;181:271-280.

2. Jothimani D, Venugopal R, Abedin MF, Kaliamoorthy I, Rela M. COVID-19 and the liver. J Hepatol 2020;73:1231-1240.

3. Zhou F, Yu T, Du R, et al. Clinical course and risk factors for mortality of adult inpatients with COVID-19 in Wuhan, China: a retrospective cohort study. Lancet 2020;395:1054-1062.

4. Xu Z, Shi L, Wang Y, et al. Pathological findings of COVID-19 associated with acute respiratory distress syndrome. Lancet Respir Med 2020;8:420-422.

5. Nardo AD, Schneeweiss-Gleixner M, Bakail M, Dixon ED, Lax SF, Trauner M. Pathophysiological mechanisms of liver injury in COVID-19. Liver Int 2021;41:20-32.

6. Kam YW, Ahmed MY, Amrun SN, et al. Systematic analysis of disease-specific immunological signatures in patients with febrile illness from Saudi Arabia. Clin Transl Immunology 2020;9:e1163.

7. Cai Q, Huang D, Yu H, et al. COVID-19: Abnormal liver function tests. J Hepatol 2020;73:566-574.

8. Yip TC, Lui GC, Wong VW, et al. Liver injury is independently associated with adverse clinical outcomes in patients with COVID-19. Gut 2021;70:733-742.

9. Guan WJ, Ni ZY, Hu Y, et al; China Medical Treatment Expert Group for Covid-19. Clinical characteristics of coronavirus disease 2019 in China. N Engl J Med 2020;382:1708-1720.

10. Huang C, Wang Y, Li X, et al. Clinical features of patients infected with 2019 novel coronavirus in Wuhan, China. Lancet 2020;395:497-506

11. Wang L, He W, Yu X, et al. Coronavirus disease 2019 in elderly patients: Characteristics and prognostic factors based on 4-week follow-up. J Infect 2020;80:639-645.

12. Wu J, Li W, Shi X, et al. Early antiviral treatment contributes to alleviate the severity and improve the prognosis of patients with novel coronavirus disease (COVID-19). J Intern Med 2020;288:128-138.

13. World Health Organization. Global health sector strategy on viral hepatitis 2016-2021. Towards ending viral hepatitis. Available from: https://apps.who.int/iris/handle/10665/246177 [Accessed 20 April 2021].

14. Wingrove C, Ferrier L, James C, Wang S. The impact of COVID-19 on hepatitis elimination. Lancet Gastroenterol Hepatol 2020;5:792-794.

15. Blach S, Kondili LA, Aghemo A, et al. Impact of COVID-19 on global HCV elimination efforts. J Hepatol 2021;74:31-36.

16. Kondili LA, Marcellusi A, Ryder S, Craxì A. Will the COVID-19 pandemic affect HCV disease burden? Dig Liver Dis 2020;52:947-949.

17. Toyoda H, Huang DQ, Le MH, Nguyen MH. Liver care and surveillance: the global impact of the COVID-19 pandemic. Hepatol Commun 2020;4:1751-1757.

18. Aghemo A, Masarone M, Montagnese S, Petta S, Ponziani FR, Russo FP; Associazione Italiana Studio Fegato (AISF). Assessing the impact of COVID-19 on the management of patients with liver diseases: A national survey by the Italian association for the study of the Liver. Dig Liver Dis 2020;52:937-941.

19. Niriella MA, Siriwardana RC, Perera MTPR, Narasimhan G, Chan SC, Dassanayake AS. Challenges for liver transplantation during recovery from the COVID-19 pandemic: insights and recommendations. Transplant Proc 2020;52:2601-2606.

20. Saracco M, Martini S, Tandoi F, et al. Carrying on with liver transplantation during the COVID-19 emergency: Report from Piedmont region. Clin Res Hepatol Gastroenterol 2020 Aug 7:101512 [Online ahead of print]. doi: 10.1016/j.clinre.2020.07.017

21. Chew CA, Iyer SG, Kow AWC, et al. An international multicenter study of protocols for liver transplantation during a pandemic: A case for quadripartite equipoise. J Hepatol 2020;73:873-881.

22. Maggi U, De Carlis L, Yiu D, et al. The impact of the COVID-19 outbreak on liver transplantation programs in Northern Italy. Am J Transplant 2020;20:1840-1848.

23. Webb GJ, Marjot T, Cook JA, et al. Outcomes following SARS$\mathrm{CoV}-2$ infection in liver transplant recipients: an international registry study. Lancet Gastroenterol Hepatol 2020;5:1008-1016.

24. Amaddeo G, Brustia R, Allaire M, et al; Paris Liver Cancer Group. Impact of COVID-19 on the management of hepatocellular carcinoma in a high-prevalence area. JHEP Rep 2021;3:100199.

25. Wong GL, Wong VW, Thompson A, et al; Asia-Pacific Working Group for Liver Derangement during the COVID-19 Pandemic. Management of patients with liver derangement during the COVID-19 pandemic: an Asia-Pacific position statement. Lancet Gastroenterol Hepatol 2020;5:776-787.

26. International Liver Cancer (ILCA). Management of HCC during COVID-19: ILCA guidance. Available from: https://afef.asso.fr/ article_actu/management-of-hcc-during-covid-19-ilca-guidance [Accessed 30 April 2021].

27. Boettler T, Marjot T, Newsome PN, et al. Impact of COVID-19 on the care of patients with liver disease: EASL-ESCMID position paper after 6 months of the pandemic. JHEP Rep 2020;2:100169.

28. Fix OK, Hameed B, Fontana RJ, et al. Clinical best practice advice for hepatology and liver transplant providers during the COVID-19 pandemic: AASLD expert panel consensus statement. Hepatology 2020;72:287-304.

29. Lleo A, Invernizzi P, Lohse AW, Aghemo A, Carbone M. Management of patients with autoimmune liver disease during COVID-19 pandemic. J Hepatol 2020;73:453-455.

30. D'Antiga L. Coronaviruses and immunosuppressed patients: the facts during the third epidemic. Liver Transpl 2020;26:832-834.

31. Brenner EJ, Ungaro RC, Gearry RB, et al. Corticosteroids, but not TNF antagonists, are associated with adverse COVID-19 outcomes in patients with inflammatory bowel diseases: results from an international registry. Gastroenterology 2020;159:481-491.

32. Gianfrancesco M, Hyrich KL, Al-Adely S, et al; COVID-19 Global Rheumatology Alliance. Characteristics associated with hospitalisation for COVID-19 in people with rheumatic disease: data from the COVID-19 Global Rheumatology Alliance physician-reported registry. Ann Rheum Dis 2020;79:859-866.

33. Montero F, Martínez-Barrio J, Serrano-Benavente B, et al. Coronavirus disease 2019 (COVID-19) in autoimmune and inflammatory conditions: clinical characteristics of poor outcomes. Rheumatol Int 2020;40:1593-1598.

34. Di Giorgio A, Nicastro E, Speziani C, et al. Health status of patients with autoimmune liver disease during SARS-CoV-2 outbreak in northern Italy. J Hepatol 2020;73:702-705.

35. Gerussi A, Rigamonti C, Elia C, et al. Coronavirus disease 2019 in autoimmune hepatitis: a lesson from immunosuppressed patients. Hepatol Commun 2020;4:1257-1262.

36. Marjot T, Buescher G, Sebode M, et al; contributing Members and Collaborators of ERN RARE-LIVER/COVID-Hep/ SECURE-Cirrhosis, Moon AM, Webb GJ, Lohse AW. SARS$\mathrm{CoV}-2$ infection in patients with autoimmune hepatitis. J Hepatol 2021;74:1335-1343.

37. Ghoneim S, Butt MU, Hamid O, Shah A, Asaad I. The incidence of COVID-19 in patients with metabolic syndrome and non- 
alcoholic steatohepatitis: A population-based study. Metabol Open 2020;8:100057.

38. Ji D, Qin E, Xu J, et al. Non-alcoholic fatty liver diseases in patients with COVID-19: a retrospective study. J Hepatol 2020;73:451-453.

39. Zhou YJ, Zheng KI, Wang XB, et al. Younger patients with MAFLD are at increased risk of severe COVID-19 illness: A multicenter preliminary analysis. J Hepatol 2020;73:719-721.

40. Zhou YJ, Zheng KI, Wang XB, et al. Metabolic-associated fatty liver disease is associated with severity of COVID-19. Liver Int 2020;40:2160-2163.

41. Targher G, Mantovani A, Byrne CD, et al. Risk of severe illness from COVID-19 in patients with metabolic dysfunction-associated fatty liver disease and increased fibrosis scores. Gut 2020;69:1545-1547.

42. Targher G, Mantovani A, Byrne CD, et al. Detrimental effects of metabolic dysfunction-associated fatty liver disease and increased neutrophil-to-lymphocyte ratio on severity of COVID-19. Diabetes Metab 2020;46:505-507.

43. Holly JMP, Biernacka K, Maskell N, Perks CM. Obesity, diabetes and COVID-19: an infectious disease spreading from the east collides with the consequences of an unhealthy western lifestyle. Front Endocrinol (Lausanne) 2020;11:582870.

44. Fondevila MF, Mercado-Gómez M, Rodríguez A, et al. Obese patients with NASH have increased hepatic expression of SARSCoV-2 critical entry points. J Hepatol 2021;74:469-471.

45. Lefere S, Tacke F. Macrophages in obesity and non-alcoholic fatty liver disease: Crosstalk with metabolism. JHEP Rep 2019;1:30-43.

46. Da BL, Im GY, Schiano TD. COVID-19 hangover: a rising tide of alcohol use disorder and alcohol-associated liver disease. Hepatology 2020;72:1102-1108.

47. Heim K, Binder B, Sagar, et al. TOX defines the degree of CD8+ $\mathrm{T}$ cell dysfunction in distinct phases of chronic HBV infection. Gut 2020 Oct 23:gutjnl-2020-322404 [Online ahead of print]. doi: 10.1136/gutjnl-2020-322404

48. Zhang X, Tan Y, Ling Y, et al. Viral and host factors related to the clinical outcome of COVID-19. Nature 2020;583:437-440.

49. Anugwom CM, Aby ES, Debes JD. Inverse association between chronic hepatitis B infection and Coronavirus disease 2019 (COVID-19): immune exhaustion or coincidence? Clin Infect Dis 2021;72:180-182.

50. Luo XH, Zhu Y, Mao J, Du RC. T-cell immunobiology and cytokine storm of COVID-19. Scand J Immunol 2021;93:e12989.

51. Tian D, Ye Q. Hepatic complications of COVID-19 and its treatment. J Med Virol 2020;92:1818-1824.

52. Zou X, Fang M, Huang J. Liver function should be monitored when treating COVID-19 in chronic HBV-infected patients. Clin Gastroenterol Hepatol 2020;18:3056-3057.

53. Lv XH, Yang JL, Deng K. Clinical outcomes of COVID-19 patients with chronic hepatitis B virus infection still need to be explored. Clin Gastroenterol Hepatol 2020;18:3055-3056.

54. Chen L, Huang S, Yang J, et al. Clinical characteristics in patients with SARS-CoV-2/HBV co-infection. J Viral Hepat 2020;27:1504-1507.

55. Zhang B, Huang W, Zhang S. Clinical features and outcomes of coronavirus disease 2019 (COVID-19) patients with chronic hepatitis B virus infection. Clin Gastroenterol Hepatol 2020;18:2633-2637.

56. Li Y, Li C, Wang J, et al. A case series of COVID-19 patients with chronic hepatitis B virus infection. J Med Virol 2020;92:2785-2791. 57. Elfiky AA. Anti-HCV, nucleotide inhibitors, repurposing against COVID-19. Life Sci 2020;248:117477.

58. Sayad B, Sobhani M, Khodarahmi R. Sofosbuvir as repurposed antiviral drug against COVID-19: why were we convinced to evaluate the drug in a registered/approved clinical trial? Arch Med Res 2020;51:577-581.

59. Jácome R, Campillo-Balderas JA, Ponce de León S, Becerra A, Lazcano A. Sofosbuvir as a potential alternative to treat the SARSCoV-2 epidemic. Sci Rep 2020;10:9294.

60. Hosseini FS, Amanlou M. Anti-HCV and anti-malaria agent, potential candidates to repurpose for coronavirus infection: Virtual screening, molecular docking, and molecular dynamics simulation study. Life Sci 2020;258:118205.

61. Rismanbaf A. Potential treatments for COVID-19; a narrative literature review. Arch Acad Emerg Med 2020;8:e29.

62. Fu L, Ye F, Feng Y, et al. Both Boceprevir and GC376 efficaciously inhibit SARS-CoV-2 by targeting its main protease. Nat Commun 2020;11:4417.

63. Chen YW, Yiu CB, Wong KY. Prediction of the SARS-CoV-2 (2019$\mathrm{nCoV}$ ) 3C-like protease (3CL pro) structure: virtual screening reveals velpatasvir, ledipasvir, and other drug repurposing candidates. F1000Res 2020;9:129.

64. Lu G, Zhang X, Zheng W, et al. Development of a simple in vitro assay to identify and evaluate nucleotide analogs against SARSCoV-2 RNA-dependent RNA polymerase. Antimicrob Agents Chemother 2020;65:e1508-e1520.

65. Jockusch S, Tao C, Li X, et al. Sofosbuvir terminated RNA is more resistant to SARS-CoV-2 proofreader than RNA terminated by remdesivir. Sci Rep 2020;10:16577.

66. Iavarone M, D’Ambrosio R, Soria A, et al. High rates of 30-day mortality in patients with cirrhosis and COVID-19. J Hepatol 2020;73:1063-1071.

67. Moon AM, Webb GJ, Aloman C, et al. High mortality rates for SARS-CoV-2 infection in patients with pre-existing chronic liver disease and cirrhosis: Preliminary results from an international registry. J Hepatol 2020;73:705-708.

68. Sarin SK, Choudhury A, Lau GK, et al; APASL COVID Task Force, APASL COVID Liver Injury Spectrum Study (APCOLIS StudyNCT 04345640). Pre-existing liver disease is associated with poor outcome in patients with SARS CoV2 infection; The APCOLIS Study (APASL COVID-19 Liver Injury Spectrum Study). Hepatol Int 2020;14:690-700.

69. Singh S, Khan A. Clinical characteristics and outcomes of coronavirus disease 2019 among patients with preexisting liver disease in the United States: a multicenter research network study. Gastroenterology 2020;159:768-771.

70. Bajaj JS, Garcia-Tsao G, Biggins SW, et al. Comparison of mortality risk in patients with cirrhosis and COVID-19 compared with patients with cirrhosis alone and COVID-19 alone: multicentre matched cohort. Gut 2021;70:531-536.

71. Qi X, Liu Y, Wang J, et al. Clinical course and risk factors for mortality of COVID-19 patients with pre-existing cirrhosis: a multicentre cohort study. Gut 2021;70:433-436. 